REVISTA X, Curitiba, volume 14, n.6,p.01-23, 2019.

\title{
O PAPEL DO ‘OUTRO’ NA INTERAÇÃO ENTRE APRENDIZES DE L2 NO DESENVOLVIMENTO DE SUA AUTONOMIA SOCIOCULTURAL
}

The Role of the "Other" in the Interaction Among L2 Learners While Developing Their Sociocultural Autonomy

\author{
Keise Pegoraro Rosa MANHÃES (SME - RJ, UFRJ) ${ }^{1}$ \\ Christine Siqueira NICOLAIDES (UFRJ) ${ }^{2}$
}

\begin{abstract}
RESUMO: Este artigo traz um recorte de uma pesquisa de dissertação de mestrado intitulada " $\mathrm{O}$ 'outro' na interação entre aprendizes de $\mathrm{L} 2^{3}$ com vistas à autonomia sociocultural" (MANHÃES, 2015), cujo objetivo foi compreender e analisar de que forma a construção da autonomia sociocultural de aprendizes de L2 pode (ou não) ser propiciada por meio da interação entre os pares ao realizarem uma tarefa em sala de aula. A pesquisa baseia-se no conceito de autonomia sociocultural proposto por Oxford (2003). Nesse modelo, a autora propõe duas versões de autonomia: sociocultural I, em que o desenvolvimento da autonomia ocorre na interação com o outro por meio da mediação com um par mais experiente e, sociocultural II, cujo objetivo principal não é a autonomia em si, mas a participação em uma comunidade de prática. A análise das interações entre aprendizes de uma turma do $9^{\circ}$ ano do Ensino Fundamental da rede pública do Rio de Janeiro, na disciplina de língua inglesa, mostrou que, por meio da interação, os aprendizes têm a oportunidade de colaborar, refletir, negociar significados etc., favorecendo, assim, o desenvolvimento da autonomia sociocultural dos membros da comunidade de prática. Em contrapartida, dificuldades e conflitos também podem surgir durante esse processo.
\end{abstract}

PALAVRAS-CHAVE: Aprendizes; Autonomia sociocultural; Interação.

\begin{abstract}
This paper is based on a Masters dissertation research entitled "The 'other' in the interaction among L2 learners aiming sociocultural autonomy" (MANHÃES, 2015). The aim of this study was to understand and analyze how the construction of sociocultural autonomy of L2 learners can (or not) be stimulated through the interaction among pairs while carrying out a task in the classroom. The research is based on Oxford's concept of sociocultural autonomy (OXFORD, 2003). In this model of leaner autonomy, the author proposes two versions of sociocultural autonomy: sociocultural I, in which the development of autonomy happens through the interaction with the other and the mediation with a more experienced partner, while in sociocultural autonomy II, the aim is not autonomy development itself, but the participation in a community of practice. The analysis of interaction among 9th graders of a public junior high school in the state of Rio de Janeiro during an English course showed that

\footnotetext{
1 Professora de Inglês do Município do Rio de Janeiro e Mestre em Linguística Aplicada pela Universidade Federal do Rio de Janeiro (UFRJ). kprkeise@gmail.com

${ }^{2}$ Professora Associada de Língua Inglesa no Departamento de Letras Anglo-Germânicas da Universidade Federal do Rio de Janeiro (UFRJ) e Pesquisadora do Programa Interdisciplinar de Pós-Graduação em Linguística Aplicada. christine.nicolaides@gmail.com

${ }^{3}$ Segunda Língua
} 
through interaction learners have the opportunity to cooperate, reflect, negotiate meanings and so on, thus favoring sociocultural autonomy development of the members in the community of practice. On the other hand, difficulties and conflicts may also arise during this process.

KEYWORDS: Interaction; Learners; Sociocultural autonomy.

\section{INTRODUÇÃO}

O presente artigo traz um recorte da dissertação $O$ 'outro' na interação entre aprendizes de L2 com vistas à autonomia sociocultural (MANHÃES, 2015), pesquisa que teve como objetivo observar e analisar os possíveis desencadeamentos do processo de interação entre aprendizes de língua inglesa ao realizarem uma tarefa em dupla ou em grupo com vistas à autonomia. Neste recorte, optou-se por discutir como essa interação pode vir a ser um elemento gerador de conflitos entre os pares e de que maneira essas possíveis dificuldades interferem no desenvolvimento da autonomia dos mesmos.

À vista disso, neste primeiro momento, faz-se necessário compreender o conceito de autonomia adotado no estudo. Isso porque a questão de autonomia no campo educacional não é contemporânea. Longe disso, já em 1762, Rousseau, em sua obra Emílio, discutia ideias sobre autonomia no aprendizado. Na visão do autor, a capacidade para a autonomia faz parte do ser humano e, por isso, os aprendizes são responsáveis por suas próprias ações e aprendem através das consequências de suas atitudes. Como resultado, se desenvolvem naturalmente sujeitos a sua própria autoridade e não a autoridade de outros.

Ao longo do tempo, discussões e proposições sobre o conceito de autonomia, em especial, na área de ensino e aprendizagem de línguas, ganharam força. No tocante ao campo da educação linguística, o conceito foi introduzido pelo Council of Europe's Modern Languages Project, que teve como fruto a fundação do Centre de Recherches et d'Applications en Langues (CRAPEL), na Universidade de Nancy, França. Ao assumir a liderança do CRAPEL, Henri Holec, em seu relatório encomendado pelo Council of Europe, definiu autonomia do aluno como a "habilidade de encarregar-se por sua própria aprendizagem" (HOLEC, 1981, p. 3), definição essa bastante utilizada por 
pesquisadores da área até a contemporaneidade ${ }^{4}$. Outras definições, como a de Dickinson (1987), surgiram na tentativa de definir o que seria autonomia. Para o autor, autonomia refere-se a uma situação de aprendizagem na qual o indivíduo manifesta uma atitude de responsabilidade. Nesse viés, autonomia no aprendizado tem relação com a atitude do aprendiz. Little (1991), por sua vez, entende que "autonomia no aprendizado de línguas depende do desenvolvimento e exercício de uma capacidade por distanciamento, reflexão crítica, tomada de decisão e ação independente" (LITTLE, 1991, p. 4). Além disso, segundo Little (1991), autonomia não é um estado imutável alcançado pelos aprendizes, ou seja, autonomia não é uma questão de "tudo ou nada", pois existem distintos graus de autonomia, que podem assumir comportamentos diferentes, dependendo da idade, do quanto ele progrediu em seu aprendizado, o que ele compreende etc. (LITTLE, 1991).

Cabe ressaltar que, apesar de importante, na definição proposta por Holec (1981), assim como nas outras aqui mencionadas, o foco está no que Nicolaides e Tílio (2011) chamam de autonomia individual. Para os autores "autonomia é uma questão mais complexa, que envolve não só o indivíduo, mas todo o contexto sócio-histórico de onde advém o aprendiz" (NICOLAIDES; TÍLIO, 2011, p. 178). Isso porque, de acordo com os autores:

o indivíduo faz parte de um contexto sócio-histórico e, como tal, é responsável por seus atos e pelas consequências daí originadas, além de exercer um papel de modificador no e do meio social no qual está inserido. Por outro lado, essa concepção não exclui a autonomia individual, a qual acreditamos da mesma forma ser importante (NICOLAIDES; TÍLIO, 2011, p. 179).

A ideia de uma autonomia voltada também para o âmbito social, na qual Nicolaides e Tílio (2011) se referem, baseia-se nos estudos de Oxford (2003) que, por seu turno, fundamenta-se na Teoria Sociocultural oriunda das ideias de Vygotsky (1998). A teoria vygotskyana entende que a mente humana é mediata e, portanto, é através da interação que o ser humano se constrói e desenvolve o seu conhecimento cognitivo e linguístico. Em seu artigo Toward a More Systematic Model of L2 Leaner Autonomy, Oxford (2003) sugere uma perspectiva sociocultural de autonomia e propõe

\footnotetext{
${ }^{4}$ Ver VIEIRA; PAIVA, 2005; CARTER, 2006; RAYA; LAMB; VIEIRA, 2007; BENSON; HUANG, 2008; MOURA FILHO, 2009; ANDRADE; CRISTOVAO, 2010; GARDNER, 2011; COSTA, 2012; FRANCO, 2013; SALBEGO; TUMOLO, 2014; SILVEIRA, 2015.
} 
duas versões: sociocultural I e sociocultural II, proposta essa que representa o conceito de autonomia no qual nos baseamos neste estudo.

A versão de autonomia sociocultural I é entendida como a autorregulação obtida por meio da interação social com um par mais experiente - que pode ser livros, tecnologia ou outros meios. Nesse sentido, a mediação possibilita que o par mais capaz forneça ao aprendiz "andaimes" (scaffolds), e viabilize que este se mova através da Zona de Desenvolvimento Potencial ou Proximal ${ }^{6}$ (ZDP). Desta forma, quando "o aprendiz menos experiente desenvolver habilidades autorregulatórias que o permita agir de forma intencional e independente", esses tipos de assistências poderão ser removidas (OXFORD, 2003, s/p).

$\mathrm{Na}$ versão de autonomia sociocultural II, autonomia não é o principal alvo e, sim, a participação em uma comunidade de prática. Essa participação se dá em um primeiro momento de maneira periférica e depois de forma mais completa. Assim, os membros considerados veteranos, ou seja, que já fazem parte daquela comunidade, podem dar assistência aos aprendizes novatos durante o processo de aquisição de novos conhecimentos.

Apesar do conceito de comunidade de prática (doravante $\mathrm{CoP}$ ) não ser dirigido especificamente à aprendizagem de línguas (seja ela materna ou adicional), Oxford (2003), ao propor o conceito de autonomia sociocultural, se apropria do referido conceito para explicar como práticas discursivas são difundidas em uma CoP.

Segundo Wenger (1998), todos os indivíduos pertencem a alguma CoP, seja em casa, na escola, no trabalho, na igreja etc. Contudo, nem toda comunidade é uma CoP. De acordo com o autor, somente a junção de três elementos configuram uma CoP, a saber: 1) o domínio, ou seja, os membros tem uma identidade definida pelo domínio de um interesse em comum; 2) a comunidade, isto é, o interesse por um domínio proporciona o engajamento dos membros em discussões, atividades, compartilhamento de informações, colaboração mútua, etc.; 3) a prática, uma vez que os membros de uma CoP são praticantes, ou seja, eles compartilham experiências, ferramentas, formas de abordar problemas recorrentes, etc. (WENGER, 1998).

Assim, partindo-se do princípio de Vygotsky de que a aprendizagem é mediada e a língua propriamente dita é o sistema mais utilizado para essa mediação, pode-se dizer

\footnotetext{
${ }^{5} \mathrm{O}$ termo scaffolding - andaime ou andaimento - foi cunhado em meados dos anos 70 por Wood, Bruner e Ross (1976), para descrever o apoio dado a uma criança ajudando-a desempenhar uma tarefa além de sua capacidade (NEWMAN, F.; HOLZMAN, L., 2002).

${ }^{6}$ Definição de ZDP.
} 
que o mesmo se dá para a aprendizagem de uma língua adicional. $\mathrm{Na}$ interação com pares mais proficientes de uma língua adicional, à medida que os menos proficientes se apropriam de novas práticas discursivas, tendem a também a se sentirem mais empoderados para interagir perante a nova comunidade de prática e, assim, desenvolverem sua autonomia. Uma autonomia que se dá sim na dimensão individual, mas mediada pelo coletivo, em outras palavras, uma autonomia sociocultural, como proposta por Oxford (2003).

Desse modo, pode-se dizer que "a autonomia cresce na interação no e com o mundo, e não em isolamento" (VIEIRA, 2007, p. 25). Partindo dessa premissa, em sala de aula, quando possibilitamos tarefas em pares ou em grupo em que os participantes tenham que negociar, refletir, competir por chances de turno de fala, tomada de turno, etc. delegamos aos aprendizes a responsabilidade pelo gerenciamento da interação, ou seja, espaço para exercerem sua agência no contexto em que estão inseridos. Compreende-se como agência "a habilidade de agir com iniciativa e efeito em um mundo socialmente construído" (HUNTER; COOKE, 2007, p. 1). No que tange à autonomia, Oxford (2003), ao propor uma na perspectiva sociocultural I, defende que o fator agência é visto como o poder de controlar o próprio aprendizado através da autorregulação, ou seja, em um primeiro momento esse novo conhecimento é mediado socialmente e, eventualmente, internalizado. Já na perspectiva de autonomia sociocultural II, a agência está refletida no aprendizado cognitivo e na ativa participação com os praticantes mais experientes. Nesse segundo parâmetro, o objetivo não é necessariamente o desenvolvimento da autonomia em si, mas a legitimação e a participação do novo membro na $\mathrm{CoP}$, como já dito anteriormente.

Ademais, ao propiciar o desenvolvimento da autonomia sociocultural dos aprendizes por meio da interação, possibilitamos que eles tenham voz, estimulando uma autonomia em que o indivíduo seja o "autor do seu próprio mundo" (PENNYCOOK, 1997, p. 45), visto que na vida em sociedade eles terão que ser capazes de enfrentar problemas e gerenciar escolhas.

Por outro lado, essa interação entre os pares nem sempre será 'um mar de rosas'. Nesse viés, Paiva (2010) destaca que

apesar de o outro poder funcionar como um andaime, ou seja, apesar de poder potencializar nossas habilidades e colocar nosso processo de aquisição em movimento, ele também pode constranger, restringir e inibir esse mesmo processo. (PAIVA, 2010, p. 4). 
Nunn (2000), por sua vez, entende que na interação entre os aprendizes de línguas, constrangimentos, estresse, ausência de negociação, omissão de ajuda e até a marginalização de um dos aprendizes pode acontecer.

Desse modo, neste recorte optou-se por discutir de que maneira essas dificuldades na interação entre os pares, ou seja, esses possíveis conflitos gerados por meio da interação, podem interferir (ou não) na promoção da autonomia sociocultural desses aprendizes. Assim, abordamos de que forma tarefas que poderiam propiciar espaço de trocas, negociação e reflexão através da interação entre os aprendizes podem se revelar um processo de omissão de ajuda, ausência de colaboração, conflito e estresse.

\section{METODOLOGIA ${ }^{7}$}

\subsection{Contexto de pesquisa}

Os dados da pesquisa empírica foram gerados no ano de 2014, em uma turma de língua inglesa do $9^{\circ}$ ano do Ensino Fundamental de uma escola municipal da rede pública de ensino no Estado do Rio de Janeiro. A escola é localizada mais especificamente na Baixada Fluminense, próxima ao centro do município de Duque de Caxias, em uma área de fácil acesso. A maioria dos alunos morava nas proximidades da escola. No ano de geração de dados da pesquisa, a instituição contava com turmas do primeiro segmento do Ensino Fundamental, atendendo inclusive alunos com deficiência auditiva, além de oferecer turmas do segundo segmento do Ensino Fundamental e do Ensino Regular Noturno Acelerado de Jovens e Adultos.

Foi possível perceber o compromisso da equipe pedagógica em trabalhar questões éticas e de formação cidadã, tanto que o tema proposto pela direção da instituição no ano letivo de 2014 foi bullying, devido à recorrente incidência dessa prática no ano anterior. Nas aulas de língua inglesa, a professora trabalhou não apenas com o tema sugerido (bullying), mas também com três tipos de preconceitos (racial, contra a mulher (sexism) e religioso), que se caracterizam igualmente importantes para a reflexão e conscientização do futuro cidadão. Assim, cada bimestre teve como foco norteador um assunto.

\footnotetext{
${ }^{7} \mathrm{Na}$ época da geração de dados (ano de 2014) ainda não era uma exigência submeter o projeto de pesquisa ao comitê de ética pela Plataforma Brasil. No entanto, foi solicitada (e concedida) uma autorização da Secretaria Municipal de Educação do município de Duque de Caxias para a realização desta investigação, bem como o consentimento dos participantes da pesquisa.
} 
A turma do $9^{\circ}$ ano observada era composta por aproximadamente 25 alunos e no período investigado - ano letivo de 2014, mais especificamente entre os meses de maio e setembro - as aulas de língua inglesa ocorriam no turno da tarde, uma vez por semana com duração de dois tempos consecutivos, sendo de 50 minutos cada tempo de aula. $\mathrm{Na}$ ocasião, o ensino de segunda língua na escola participante da pesquisa era norteado por dois documentos: 1) a Lei de Diretrizes e Bases (Lei 9394/95) - LDB; e 2) os Parâmetros Curriculares Nacionais de Língua Estrangeira - PCN. O material didático adotado era o livro Onstage, fornecido pelo Governo Federal por meio do PNLD ${ }^{8}$. Contudo, até o início da geração de dados (maio de 2014) não havia exemplares para todos os alunos. Por isso, frequentemente, a professora participante elaborava materiais e providenciava cópias para cada aula.

\subsection{Participantes}

Durante a pesquisa, optou-se por manter o foco de observação sob três participantes que de forma recorrente realizavam as tarefas em conjunto e que mais chamaram atenção: RITA, KARINA e ISABELA, além da professora da turma, PATRÍCIA $^{9}$. À medida que outros alunos interagiram com as participantes ${ }^{10}$, os dados decorrentes dessa interação também foram registrados e analisados. Dentre as aprendizes, RITA se destacou, em um primeiro momento, por aparentar ser uma aluna proativa e participativa que, muitas vezes, estimulava as colegas. Já KARINA, apesar de (supostamente) não ser tão proativa quanto RITA, se mostrava engajada e em interação com as tarefas propostas pela professora. ISABELA, por seu turno, pouco se pronunciava em sala de aula e era a mais tímida do grupo.

A faixa etária dos aprendizes estava entre 13 e 16 anos na época da geração de dados. A turma era tida pela professora participante como um grupo tranquilo e sem problemas no tocante à disciplina. Em alguns momentos eles pareciam estar mais agitados, contudo, nada que prejudicasse de forma significativa o andamento da aula. Além disso, a grande maioria se mostrava engajada com as tarefas propostas, bem como interessados na matéria estudada.

A professora participante, por sua vez, na ocasião era doutoranda em um curso de Linguística Aplicada e demonstrava uma rica experiência tanto no manejo do

\footnotetext{
${ }^{8}$ PNLD - Plano Nacional do Livro Didático.

${ }^{9}$ Todos os nomes são fictícios, a fim de garantir a proteção de identidade dos participantes.

${ }^{10}$ Por serem vários, eles terão seus nomes citados apenas quando aparecerem nos dados.
} 
conteúdo a ser ensinado, quanto em trabalhar com uma turma repleta de adolescentes. Ela estava sempre solícita a ouvir aos questionamentos e opiniões dos alunos, além de, constantemente, estimular a participação dos aprendizes fazendo com que suas vozes fossem ouvidas e valorizadas. Para a professora participante, língua deveria ser vista como prática social e não como formas linguísticas abstratas - conceito que também se alinha à proposta deste estudo.

\subsection{Geração de dados}

Como mencionado anteriormente, a geração de dados do estudo ocorreu durante o ano letivo de 2014, mais especificamente entre os meses de maio e setembro. Durante esse período, um total de 10 aulas de língua inglesa foram assistidas. Decidiu-se, então, por uma pesquisa com princípios etnográficos (MATTOS, 2011) e análise qualitativa, uma vez que o objetivo principal não estava no resultado final, ou seja, se o aprendiz se tornou mais ou menos autônomo, e sim no processo de construção de autonomia por meio da interação.

Com base nisso, três instrumentos de geração de dados foram adotados na intenção de trazer à tona diferentes perspectivas sobre o que acontecia no contexto de pesquisa: 1) Observação das aulas, gravando-as em áudio com um aparelho celular e posteriormente transcrevendo-as para análise ${ }^{11}$; 2) diário de pesquisa; e 3 ) entrevistas.

Durante a observação das aulas, foi possível ter acesso ao que os participantes fizeram e não apenas ao que os mesmos poderiam dizer que fizeram. No tocante ao instrumento diário de pesquisa, todas as reflexões, frustrações e principais impressões da pesquisadora durante a investigação puderam ser registradas. Já as entrevistas, por sua vez, foram usadas na tentativa de extrair o que não pode ser observado. Em outras palavras, os sentimentos, pensamentos, intenções, etc. visto que, por meio da entrevista tem-se a possibilidade de entender as reações dos participantes ao que está ali acontecendo (DORNYEI, 2007).

Assim, por meio desses três instrumentos, foi possível entender melhor as percepções dos participantes. Em princípio, as notas do diário de pesquisa foram analisadas com o objetivo de selecionar os aspectos que mais chamassem a atenção e relembrar fatos importantes que aconteceram no decorrer da investigação. Em seguida, foi realizada a análise da transcrição de áudio das aulas observadas. Nessa fase foram

\footnotetext{
${ }^{11}$ Convenções para a transcrição em anexo.
} 
destacados os instantes em que a interação entre os aprendizes acontecia. A intenção foi sinalizar as implicações desencadeadas desse processo. Após essa etapa foi feita a análise da entrevista realizada com a aprendiz e, finalmente, a análise da entrevista com a professora participante. Posteriormente, após a leitura e releitura, os dados gerados foram organizados em três categorias ${ }^{12}$. A escolha de cada categoria se deu devido à sua recorrência e relevância no contexto investigado e não por um estabelecimento a priori. Para este recorte, optou-se por trazer à tona a categoria Dificuldades na interação entre os aprendizes.

Desse modo, após caracterizar brevemente cada instrumento utilizado para a geração de dados deste estudo e, antes de prosseguir para a próxima seção, um quadro que ilustra esses instrumentos e seus objetivos no contexto da pesquisa será apresentado.

Quadro 1 - Instrumentos de geração de dados utilizados na pesquisa e respectivos objetivos.

\begin{tabular}{|c|c|}
\hline \multicolumn{2}{|c|}{ INSTRUMENTOS DE GERAÇÃO DE DADOS } \\
\hline INSTRUMENTOS & OBJETIVOS \\
\hline Observação e registro em áudio das aulas & $\begin{array}{l}\text { - Conhecer e descrever o contexto observado e os } \\
\text { participantes envolvidos; } \\
\text { - Observar o que acontecia na interação entre os } \\
\text { alunos ao realizarem uma tarefa em grupo ou em } \\
\text { pares. }\end{array}$ \\
\hline Diário de pesquisa & $\begin{array}{l}\text { - Registrar os fatos relevantes a fim de não } \\
\text { esquecê-los no decorrer da investigação; } \\
\text { - Auxiliar na análise e na interpretação dos dados. }\end{array}$ \\
\hline Entrevista com a aprendiz & $\begin{array}{l}\text { - Complementar as informações obtidas por meio } \\
\text { de outros instrumentos tendo acesso à perspectiva } \\
\text { da participante. }\end{array}$ \\
\hline Entrevista com a professora & $\begin{array}{l}\text { - Conhecer a percepção da professora } \\
\text { sobre sua prática e sua visão de linguagem } \\
\text { no contexto de ensinagem }{ }^{13} \text { de línguas. }\end{array}$ \\
\hline
\end{tabular}

Fonte: as autoras

$\mathrm{Na}$ seção a seguir, selecionamos alguns dados que demonstram possíveis conflitos e tensões durante a interação entre os aprendizes. Dessa forma, procuraremos identificar e analisar como essas dificuldades surgidas através da interação interferiram (ou não) no fomento da autonomia dos pares.

\footnotetext{
${ }^{12}$ As três categorias alavancadas foram: 1) Quando as vozes parecem se equiparar; 2) Quando o colega é o líder; e, 3) Dificuldades na interação entre os aprendizes.

${ }^{13}$ O termo "ensinagem" tem sido adotado na intenção de substituir os termos "ensino e aprendizagem" ou "ensino-aprendizagem", não marcando, desta forma, sua dicotomia, mas estabelecendo uma íntima relação, ou seja, um processo de parceria. (HAMZEZ, [201-]).
} 


\section{ANÁLISE E DISCUSSÃO DE DADOS}

Ao propor tarefas em pares ou em grupos em sala de aula, muitas das vezes, possibilitamos aos aprendizes oportunidades de negociar, cooperar, refletir, competir por chances de turno de fala, etc., uma vez que a responsabilidade pelo gerenciamento da interação é delegada aos pares. Além disso, por meio dessas tarefas, propiciamos oportunidades para que os participantes tenham voz e ensaiem "a experiência profunda do assumir-se" (FREIRE, 2014, p. 42). Como resultado, potencializamos o fomento da autonomia sociocultural dos mesmos. Entretanto, isso sempre será possível? Nos excertos a seguir destacamos alguns exemplos de como a interação entre os aprendizes pode funcionar também como um possível elemento inibidor da autonomia.

$\mathrm{Na}$ aula de 22/08/2014, a fim de promover uma construção conjunta do significado do termo sexism, a professora apresenta algumas propagandas ${ }^{14}$ em língua inglesa e propõe a seguinte tarefa em grupo:

\section{Excerto 01 - Transcrição da aula gravada em 22/08/2014}

PATRÍCIA: (.) vocês vão fazer o levantamento das propagandas vão supor ( ) o que que fala aqui sobre as mulheres? as mulheres devem o quê? ah.. essas características, a segunda o que que então tá falando sobre ( ) vocês vão listar em todas as propagandas como que a mulher está sendo representada. o exercício dois ( ) qual o objetivo delas?() e no três vocês vão discutir na opinião de vocês, não tem certo nem errado tá? você só não pode falar essa aqui. por quê? não sei, não entendi o que tá escrito, mas é essa aqui. não pode tá? então você vai ter que justificar

A tarefa deveria ser feita em grupo e o grupo observado no dia 22/08/2014 era composto pelas aprendizes KARINA, ISABELA e JÉSSICA. Porém, logo em seguida, a participante RITA chega e também se integra à equipe, como destacamos no excerto a seguir:

Excerto 02 - Observações de aula - 22/08/2014

Rita chega no $2^{\circ}$ tempo e se junta ao grupo da Jéssica, Isabela e Karina. (...) Rita copiou a matéria do quadro, mas não participou da execução da tarefa. Até este momento, Karina participou ativamente. Por várias vezes, ela foi até a professora perguntando o sgdo ${ }^{15}$ de algumas palavras, pesquisando no

\footnotetext{
${ }^{14}$ Em anexo.

${ }^{15}$ Cumpre ressaltar que mantivemos os dados inalterados, com exceção dos nomes dos participantes envolvidos, a fim de manter a privacidade dos mesmos. Assim, a abreviação "sgdo" que indica
} 
dicionário, etc.(...) Rita ficou no face pelo celular. Karina, por outro lado, sempre ficava em pé p/ procurar e perguntar a professora questões relacionadas à tarefa. Rita, no entanto, não participa.

No excerto anterior, observamos a falta de compromisso da aprendiz RITA para com a tarefa proposta. Ela não auxilia as colegas nem mesmo com a tradução de alguns vocábulos. Pelo contrário, prefere permanecer ao celular acessando o Facebook a maior parte do tempo. Dessa forma, não há nenhum tipo de negociação ou colaboração por parte da aprendiz com o grupo. Evidenciamos, portanto, um descaso com a $\mathrm{CoP}$ em que a aprendiz está inserida. Cabe salientar que, embora a tarefa proposta pela professora potencialize a promoção da autonomia dos aprendizes, uma vez que a autorregulação é propiciada através da interação social, RITA escolhe não participar desse processo. Por algum motivo, RITA não se engaja e nem se esforça em colaborar, ficando, como destacado por Wenger (1998), marginal à prática situada da comunidade naquele momento.

Em outra ocasião - aula do dia 19/09/2014 -, o mesmo fenômeno é observado, mas agora com um agravante, pois é dia de avaliação e a correta realização da tarefa implicará em nota para o $3^{\circ}$ bimestre. Além disso, a avaliação deve ser feita em dupla. Veja as observações de aula desse dia.

Excerto 03 - Observações de aula - 19/09/2014

(...) Isabela levanta e tira foto das propagandas do quadro. Em seguida, escreve no caderno. Rita apenas observa. Isabela e Rita estão quietas.

(...) Isabela e Rita não parecem uma dupla, pois apenas Isabela escreve e Rita olha p/os lados.

Mais uma vez, a aprendiz RITA não se engaja e nem se responsabiliza pela execução da tarefa proposta. Como resultado, todo o trabalho precisa ser feito por ISABELA. Desse modo, a interação entre os pares é caracterizada pela omissão de ajuda, ausência de colaboração e estresse. O "outro", portanto, ao invés de ajudar e contribuir com o par, acaba por atrapalhar gerando conflitos e tensões durante a interação na CoP.

Segundo Walesko (2019), apesar do termo comunidade apresentar a priori uma conotação positiva, conflitos também fazem parte das relações entre os membros nas

"significado", foi escrita dessa forma, pois no momento da geração de dados essa foi a maneira que o termo foi registrado pela pesquisadora nas observações da aula. 
práticas da comunidade. Para a autora, os conflitos, em geral, são produtivos, pois sem eles não há aprendizagem ou desenvolvimento nas CoPs. Halu (2010), por sua vez, ressalta que "toda comunidade enfrenta o desafio de desenvolver um equilíbrio dinâmico entre seus desejos de consenso e mudança, tendo de lidar com conflitos como elemento constante em sua existência" (HALU, 2010, p. 60). Dessa maneira, segundo a autora, para haver mudanças e reavaliações, torna-se imprescindível o modo como a comunidade irá lidar com os conflitos surgidos. Na ocasião exposta, ISABELA, contudo, parece não apresentar nenhuma reação à omissão de ajuda de RITA. Apesar do conflito surgido, ISABELA prefere realizar a tarefa sozinha a negociar mudanças no comportamento de RITA.

Além do fenômeno observado anteriormente, outro tipo de dificuldade pode surgir durante as interações entre os aprendizes: o apagamento ou marginalização de uma das participantes do grupo. Foi o que aconteceu durante a aula do dia 18/07/2014. KARINA, ISABELA e RITA destacavam as palavras cognatas nas letras de música trazidas por elas quando uma das participantes tem sua voz apagada no grupo. Veja a transcrição abaixo:

Excerto 04 - Transcrição da aula gravada em18/07/2014

KARINA: vai fazer o trabalho sozinha mesmo?

ISABELA: quê?

KARINA: (vai fazer o trabalho sozinha?)

ISABELA: não, eu só vou circular aqui as palavras cognatas

RITA: porque eu só vou copiar. então você cala a sua boca porque até agora você não fez nada.

KARINA: Hh

RITA: não botou nem o nome da $m^{* 16}$ da escola

KARINA: Hh. (quê?)

RITA: CALA A BOCA

KARINA: $\mathrm{Hh}$

Percebemos que, mesmo KARINA indicando algum interesse pela tarefa proposta, RITA toma o turno e a impede de qualquer tipo de participação. KARINA, entretanto, parece não se importar com a coibição da colega, pois apesar da forma com que RITA se dirige a ela, a aprendiz simplesmente ri (Hh). Todavia, essa restrição à participação da aprendiz KARINA na CoP continua e ela tem novamente a sua voz apagada, como podemos observar no excerto seguinte:

\footnotetext{
${ }^{16} \mathrm{O}$ símbolo gráfico faz referência ao uso de palavra de baixo calão, que evitamos aqui reproduzir.
} 
Excerto 05 - Transcrição da aula gravada em 18/07/2014

RITA: é... (2.4) longer. que que significa longer é longe?

ISABELA: não. é perto.

KARINA: longer não é longe

RITA: cala a sua boca que eu falei com a Isabela.

KARINA: mas longer não é longe?

RITA: mas tem que ver ( )

KARINA: mas, caraca vocês são retardadas cara?

RITA: se tiver errado a gente pelo menos tentou.

KARINA: $\mathrm{Hh}$

Embora KARINA tente colaborar com a atividade, novamente RITA a impede. Dessa vez, no entanto, KARINA parece estar disposta a lutar para fazer valer a sua voz, tanto que enfatiza que "longer não é longe", mas RITA não leva em consideração a contribuição de KARINA e, logo argumenta que se a resposta estiver incorreta, "a gente pelo menos tentou". O pronome "a gente", contudo, parece não incluir KARINA e, sim, ISABELA e a própria RITA. Assim, o "outro" (RITA) marginaliza o seu par durante a interação, uma vez que constrange e até coíbe a participação deste na CoP.

Segundo Lantolf e Pavlenko (2000), quando a participação é alvo de constrangimento, marginalização ou até mesmo de restrição, o aprendiz fica impedido de exercer a sua agência. Como agentes, os aprendizes podem se engajar de forma ativa e construir os termos e as condições de sua aprendizagem. Dessa forma, à medida que a agência de KARINA é impossibilitada, o desenvolvimento de sua autonomia no âmbito sociocultural também sofre as consequências. Isso porque, na proposta de autonomia Sociocultural II de Oxford (2003), o objetivo principal do aprendiz não é a autonomia em si, mas a participação em uma CoP. Assim, a agência está refletida no aprendizado cognitivo e na ativa participação com os praticantes mais experientes, fato que não acontece com KARINA no fragmento apresentado.

Em um momento posterior na mesma aula do dia 18/07/2014, as aprendizes continuam procurando por palavras cognatas nos textos e, mais uma vez, conflitos e tensões surgem durante a interação. Observe o excerto abaixo:

Excerto 06 - Transcrição da aula gravada em 18/07/2014

RITA: tá quase acabando. vou comer doce (2.4) cara eu vou morrer de diabete. KARINA: eu tenho tendência a ter diabete.

RITA: eu não te perguntei nada. 


\section{KARINA: $f^{* 17}$ mas eu tô falando \\ (...) \\ KARINA: me empresta ( ) \\ RITA: ah ô você não tá fazendo nada ( ) \\ KARINA: é claro minha letra é feia \\ RITA: cala a boca \\ KARINA: ( ) \\ RITA: cala a boca \\ KARINA: ( ) não se mete \\ RITA: sua insignificante \\ KARINA: Hh você é chata. insignificante é tua mãe \\ RITA: é mesmo (.) só serviu pra me botar no mundo}

No excerto anterior, KARINA parece enfrentar de uma forma mais enfática as proibições de RITA. Sob nosso ponto de vista, trata-se de uma questão de empoderamento. Como concepção de empoderamento compreendemos, assim como Schrader (2003), como "os processos de auxiliar os aprendizes a tornarem-se conscientes de que possuem um impacto no seu ambiente e podem exercer algum controle sobre suas circunstâncias" (SCHRADER, 2003). Assim, podemos observar que RITA tenta fazer valer sua voz e busca alternativas para trazer de volta o seu turno de fala. De alguma maneira, a aprendiz empodera-se e luta pelo seu espaço. RITA, em contrapartida, também reage. Não é possível confirmar, no entanto, se o real sentimento de RITA pela mãe é revelado ou se foi apenas uma maneira de não ficar "por baixo" em relação à atitude de KARINA. Porém, verificamos que por meio do conflito surgido, KARINA parece aprender a se posicionar e exercer a sua agência no grupo.

Como mencionamos no início deste artigo, entendemos que por meio da interação existe um potencial para o desenvolvimento da autonomia entre os aprendizes. Entretanto, observamos nos excertos anteriores, questões de empoderamento e disputa por território que levaram a um consequente conflito e tensão durante essa interação. Contudo, acreditamos que as dificuldades surgidas nas interações entre os pares se fazem igualmente importantes para o fomento da autonomia dos mesmos. Isso porque, quando os aprendizes refletem e buscam alternativas para os desafios encontrados, eles aprendem a enfrentar situações que estarão presentes dentro e fora do ambiente escolar.

Ao se falar de conflitos entre pares ocorridos em uma ZDP faz-se necessário trazer à tona, mais uma vez, o conceito de Zona de Desenvolvimento Proximal (ZDP), inicialmente proposta por Vygotsky (1978). Segundo Fino (2001):

\footnotetext{
${ }^{17}$ Mais uma vez, o símbolo gráfico faz referência ao uso de palavra de baixo calão, que evitamos aqui reproduzir.
} 


\begin{abstract}
um aspecto particularmente importante da teoria de Vygotsky é a ideia da existência de uma área potencial de desenvolvimento cognitivo, definida com a distância que medeia entre o nível actual da criança, determinado actual de resolver problemas individualmente, e o nível de desenvolvimento potencial, determinado através da resolução de problemas sob a orientação de adultos ou em colaboração com pares mais capazes (FINO, 2001, p. 5).
\end{abstract}

Por outro lado, se a ZDP é um espaço em que há potencial para a aprendizagem acontecer é também um espaço que podem ocorrer conflitos entre os pares interactantes. Nesse sentido, Szundy (2009, p. 101) nos lembra sobre definição de ZDP de Bernstein que a define como "palco para batalhas ideológicas" (BERSTEIN, 1993 apud SZUNDY, 2009, p. 101). Neste "palco", segundo Szundy, "conflitos e embates contribuem para que as peças do quebra-cabeça sejam encaixadas e desencaixadas à medida que o conhecimento, como um espiral, passou por mesmo ponto a cada nova revolução" (SZUNDY, 2009, p. 101).

Dessa maneira, vimos que, mesmo nas interações em que conflitos e estresse podem surgir, existe espaço para que o desenvolvimento da autonomia sociocultural aconteça. Em consonância a Vygotsky (1998), entendemos que a ZDP não é apenas uma zona de colaboração e compreensão na produção de significados. Pelo contrário, ela é também um espaço de conflitos e contradições que também são necessários para que o desenvolvimento aconteça. Nesse sentido, ao lidar com algumas dificuldades durante a interação, o aprendiz estará vivenciando situações da vida real desenvolvendo sua autonomia sociocultural e aprendendo em sala de aula a "constituir-se sujeito do discurso" (BRASIL, 1998, p. 60), como também defendemos neste artigo.

À vista disso, as aprendizes aqui analisadas por meio de suas falas na interação com seus pares, apesar dos conflitos gerados a partir de uma disputa de território para fazerem valer suas vozes, mostram agência e empoderamento. Ainda que de uma forma pouco construtiva, no sentido de parecer não conseguirem avaliar que o conhecimento se dá no social e para que ele ocorra é preciso negociar e avaliar as hipóteses durante a interação, o fato das aprendizes lutarem por seus espaços pode ser visto como forma de desenvolvimento de sua autonomia sociocultural. A interação entre as participantes nesta situação se apresenta como um espaço para que suas disputas sirvam para fazer valer suas vozes, disputas que podem ser vistas como uma tentativa de serem aceitas na nova CoP, nesse caso, uma comunidade de aprendizes de língua inglesa que lutam para serem reconhecidas e legitimadas como usuárias da língua inglesa. 


\section{CONSIDERAÇÕES FINAIS}

No presente cenário global, na era planetária $^{18}$ conforme salientado por Edgar Morin (2003), o ambiente escolar é estratégico para o desenvolvimento de habilidades cognitivas, culturais e sociais essenciais aos cidadãos do futuro. Dessa forma, o fomento de uma autonomia não apenas individual, mas voltada para o plano social, constitui-se indispensável no âmbito educacional. Entretanto, propor o desenvolvimento da autonomia sociocultural por meio da interação em sala de aula nem sempre será uma tarefa fácil. Conforme elucidado nos excertos deste recorte, a interação com o 'outro' pode vir a ser um elemento gerador de conflitos e contradições.

Por outro lado, divergências e tensões fazem parte da ZDP, pois esses eventos também são relevantes para o desenvolvimento cognitivo do aprendiz (VYGOTSKY, 1998), uma vez que a ZDP é "palco para batalhas ideológicas" (BERSTEIN, 1993 apud SZUNDY, 2009, p. 101), conforme já apontado neste trabalho. Nesse mesmo viés, Halu (2010) entende que

[...] os conflitos podem gerar oportunidades para fortalecer comunidades, pois no conflito encontra-se a ocasião de examinar diferenças de crenças, solicitar vozes alternativas, construir pontes entre diferenças em direção a um solo comum e procurar oportunidades para mudança e crescimento (HALU, 2010, p. 60).

Assim, constatamos que nas situações aqui apresentadas, houve espaço para o desenvolvimento da autonomia dos aprendizes, apesar da interação entre eles não ter sempre apresentado situações de tranquilidade. Isso aconteceu quando a aprendiz KARINA aprendeu a buscar soluções diante de situações conflituosas e a empoderar-se por meio de uma autonomia em que fosse responsável não apenas por sua aprendizagem, mas também por agir de forma crítica e transformadora na sociedade em que vive. Além disso, enquanto KARINA buscou exercer a sua agência, ou seja, fazer valer a sua voz na CoP na qual estava inserida, o desenvolvimento de sua autonomia no âmbito sociocultural pôde ser potencializado.

Vale ressaltar que a percepção dos conflitos e tensões durante a interação entre os pares só foi possível devido à análise e reflexão dos dados gerados pelos instrumentos de pesquisa. O professor, em sala de aula, muitas vezes nem teria ciência

\footnotetext{
${ }^{18}$ A era planetária, segundo Morin (2003), é marcada pelo descobrimento da América e a navegação ao redor do mundo, bem como a constatação de que a terra girava, na verdade, em torno do sol. Teve seu início entre o final do século XV e o início do XVI e se caracterizou, em especial, pelo estreitamento de relações entre povos de partes distintas do planeta.
} 
de todos os eventos propiciados pela interação no fomento (ou não) da autonomia sociocultural dos aprendizes. Dessa forma, destacamos a relevância de inquirições neste viés para o campo educacional.

Outrossim, entendemos que ao desenvolver, dentro do campo da Linguística Aplicada (LA), uma pesquisa que observe a interação com vistas à autonomia sociocultural do aprendiz, investigamos a questão da reflexão, da negociação, da tomada de turno por parte do aprendiz como um fator necessário para que sua voz não seja alvo de marginalização ou apagamento. Dessa maneira, privilegiamos uma autonomia em que o indivíduo seja "capaz de fazer valer sua voz dentro de sua própria cultura e saber tanto reconhecer, como exaltar ou como questionar os valores nela inseridos" (NICOLAIDES, 2003, p. 45). Assim, apresentamos uma pesquisa dentro da LA que pode colaborar na construção "de um novo paradigma social” (MOITA, 2006, p. 104).

Portanto, estimulamos e encorajamos futuras investigações sobre o tema. Ainda há muito a ser esmiuçado. A título de exemplo, acreditamos ser fundamental trazer à luz pesquisas que tratem de que maneira o trabalho com o livro didático pode interferir (ou não) no desenvolvimento da autonomia sociocultural dos aprendizes durante a interação. Além disso, estudos sobre a construção dessa autonomia em um ambiente online também são relevantes. Isso porque, em plena era virtual, inquirições que descrevam e analisem de que maneira a autonomia sociocultural dos pares pode ser propiciada (ou não) através desse tipo de interação se fazem igualmente significativas para o avanço da área. Reconhecemos que não é e nem será uma tarefa fácil, mas entendemos que "somente almejando mais, alcançaremos mais" (TILIO, 2012).

\section{REFERÊNCIAS}

ANDRADE, J.; CRISTOVAO, V. Autonomia na formação de professores por meio de gêneros textuais. Semina: Ciências Sociais e Humanas, Londrina, v. 31, n. 2, p. 145162, jul./dez. 2010. Disponível em: <http://pt.slideshare.net/perillojose1/autonomia-naformao-de-professores-por-meio-de-gneros-textuais>. Acesso em: 20 dez. 2018.

BENSON, P. Teaching and Researching Autonomy in Language Learning. Malaysia: Pearson Education Limited, 2001.

BENSON, P; HUANG, J. Autonomy in the transition from foreign language learning to foreign language teaching. DELTA v. 24, $\mathrm{n}^{\circ}$ spe. São Paulo, 2008. Disponível em: <http://www.scielo.br/scielo.php?script=sci_arttext\&pid=S0102-44502008000300003> Acesso em: 10 jan. 2019. 
BRASIL. Secretaria de Educação Fundamental. Parâmetros Curriculares Nacionais. terceiro e quarto ciclos do ensino fundamental: língua estrangeira/Secretaria de Educação Fundamental. Brasília: MEC/SEF, 1998. p. 120.

CARTER, B. Teacher/Student Responsibility in Foreign Language Learning. New York: Peter Lang Publishing, 2006.

COSTA, M. Autonomia do aluno na sala de aula de língua portuguesa: uma proposta de atividade articulando línguas e linguagem. Tese de Doutorado. Araraquara: UNESP, 2012. Disponível em: <http://wwws.fclar.unesp.br/agenda-pos/linguistica_lingua_ portuguesa/2740> Acesso em: 03 dez. 2018.

DICKINSON, L. Self-instruction in Language Learning. Cambridge: University Press, 1987.

DORNYEI, Z. Research Methods in Applied Linguistics. Oxford: OUP, 2007.

FINO, N. Vygotsky e a Zona de Desenvolvimento Proximal (ZDP): Três implicações pedagógicas. Revista Portuguesa de Educação, v. 14, n. 2, 2001. Universidade do Minho, Braga, Portugal, 2001.

FRANCO, C.; Revisitando o conceito de autonomia no ensino aprendizagem de línguas como sistema adaptativo e complexo. Educação em revista, v. 29, n. 3. Belo Horizonte, 2013. Disponível em: <http://www.scielo.br/scielo.php?pid=S0102-469820130003000 06\&script=sci_arttext $>$ Acesso em: 23 nov. 2018.

FREIRE, P. Pedagogia da Autonomia: saberes necessários à prática educativa. 49a ed. Rio de Janeiro: Paz e Terra, 1996/2014.

GARDNER, D. Fostering Autonomy in Language Learning.Turkey: Zirve University, 2011.

HALU, R. Formação de formadoras de professoras de inglês em contexto de formação continuada (NAP-UFPR). Tese de Doutorado, Curso de Pós-Graduação em Letras, Setor de Ciências Humanas, Letras e Artes, Universidade Federal do Paraná. Curitiba, 2010. Disponível em: <http://www.educadores.diaadia.pr.gov.br/arquivos/File /2010/artigos_teses/2010/Ingles/teses/reginahalu.pdf>. Acesso em: 15 jul. 2019.

HAMZE, A. A construção e articulação dos saberes. [201-]. Disponível em: <http://educador.brasilescola.com/trabalho-docente/articulacao-saberes.htm>. Acesso em: 18 nov. 2019.

HOLEC, H. Autonomy in Foreign Language Learning. Oxford: Pergamon, 1981.

HUNTER, J.; COOKE, D. Through autonomy to agency: Giving power to language learners. In: Prospect v. 22, n. 2, 2007.

LANTOLF, J.; PAVLENKO, A. Introducing sociocultural theory. In: LANTOLF, J. (Ed.) Sociocultural theory and second language learning. Oxford: Oxford University Press, 2000. p. 1-26. 
LITTLE, D. Learner Autonomy 1: Definitions, issues and problems. Dublin: Authentik, 1991.

MATTOS, C. A abordagem etnográfica na investigação científica. In: MATTOS, C.; CASTRO, P. (orgs.) Etnografia e educação: conceitos e usos [online]. Campina Grande: EDUEPB, 2011, p. 49-83.

MOITA, L. Linguística Aplicada e contemporaneidade: problematização dos construtos que têm orientado a pesquisa. In: MOITA LOPES, L. P. (Org.) Por uma Linguística Aplicada INdisciplinar. São Paulo: Parábola, 2006.

MORIN, E.; CIURANA, E.; MOTTA, R. Educar na Era Planetária: O pensamento complexo com Método de aprendizagem no erro e na incerteza. São Paulo: Cortez Editora, 2003. ISBN 85-249-0937-4. Disponível em: $<$ http://www.uesb.br/labtece/artigos/Edgar\%20Morin\%20\%20Educar\%20na\%20Era\%2 0planet\%C3\%A1ria.pdf> Acesso em: 10 jan. 2019.

MOURA FILHO, A. O que há em um nome? O estado-da-arte da autonomia na aprendizagem de línguas. Linguagem \& Ensino, Pelotas, v.12, n.1, p. 253-283, jan./jun. 2009. Disponível em: <https://docplayer.com.br/81335607-O-que-ha-em-um-nome-oestado-da-arte-da-autonomia-na-aprendizagem-de-linguas.html> Acesso em: 03 jan. 2019.

NICOLAIDES, C. A busca da aprendizagem autônoma de línguas no contexto acadêmico. Tese de doutorado. Universidade Federal do Rio Grande do Sul, Porto Alegre, 2003.

NICOLAIDES, C.; TILIO, R. O Material Didático na promoção da aprendizagem autônoma de línguas por meio do Letramento Crítico. In: SZUNDY, P.; ARAÚJO, J.; NICOLAIDES, C.; SILVA, K. (Orgs.). Linguística Aplicada e Sociedade: Ensino e Aprendizagem de Línguas. Campinas: Pontes Editores, 2011.

NUNN, R. Designing rating scales for small-group interaction. Oxford University Press ELT Journal v. 54/2, p. 169-178, 2000.

OXFORD, R. Toward a More Systematic Model of L2 Learner Autonomy. In: PALFREYMAN, D. (ed.) Learner Autonomy Across Cultures. Great Britain: Macmillan, 2003.

PAIVA, V. O outro na aprendizagem de línguas. In: HERMONT, A. B.; ESPÍRITO SANTO, R. S.; CAVALCANTE, S. M. S. Linguagem e cognição: diferentes perspectivas, de cada lugar um outro olhar. Belo Horizonte: Editora PUC MINAS, 2010. p. 203-217.

PENNYCOOK, A. Cultural Alternatives and Autonomy. In: BENSON, P.; VOLLER, P. Autonomy and Independence in Language Learning. New York: Addison Wesley Longman, 1997. p. 35-53. 
RAYA, M.; LAMB, T.; VIEIRA, F. Pedagogia para a autonomia na Educação em Línguas na Europa - Para um quadro de Referência do Desenvolvimento do Aluno e do Professor. Dublin: Authentik, 2007.

MANHÃES, Keise Pegoraro Rosa. $O$ 'outro' na interação entre aprendizes de L2 com vistas à autonomia sociocultural. Dissertação de Mestrado. Programa Interdisciplinar de Pós-Graduação em Linguística Aplicada, Faculdade de Letras, Universidade Federal do Rio de Janeiro. Rio de Janeiro, 2015.

ROUSSEAU, J. Emílio ou da Educação. Tradução de Roberto Leal Ferreira. $2^{a}$ ed. São Paulo: Martins Fontes, 1999.

SALBEGO, N.; TUMOLO, C. Autonomia na aprendizagem de línguas em EAD: Percepção de alunos com relação ao desenvolvimento das quatro habilidades em inglês. XI Congresso Brasileiro de Ensino Superior a Distância. Florianópolis, 05 a 08 de agosto de 2014. Disponível em: <http://esud2014.nute.ufsc.br/anaisesud2014/files/pdf/126731.pdf>. Acesso em: 22 nov. 2018.

SHRADER, S. Learner Empowerment - A Perspective. The Internet TESL Journal, v. IX, n. 11, November 2003. Disponível em: <http://iteslj.org/Articles/ShraderEmpowerment.html>. Acesso em: 18 nov. 2019.

SILVEIRA, R. Crenças docentes: motivação e autonomia na aprendizagem de inglês como LE. Dissertação de Mestrado. Universidade de Brasília, 2015. Disponível em: <http://repositorio.unb.br/handle/10482/18455> Acesso em: 08 nov. 2018.

SZUNDY, P. Zona de desenvolvimento potencial: uma zona de conflitos e revoluções no diálogo pesquisadora-professores. In: SCHETTINI, R. H. et al. Vygotsky: uma revista no início do século XXI. São Paulo: Andross, 2009.

TILIO, R. Notas de Aula da Disciplina de Mestrado Introdução à Linguística Aplicada. Rio de Janeiro: UFRJ, 2012.

VIEIRA, L.; PAIVA, V. A formação do professor e a autonomia na aprendizagem de língua inglesa no Ensino Básico, 2005.

VIEIRA, F. Addressing constraints on autonomy in school contexts: lessons from working with teachers. In: D. PALFREYMAN \& R. C. SMITH (Eds.). Learner Autonomy across Cultures: Language Education Perspectives. Basingstoke: Palgrave Macmillan, 2007, p. 220-239.

VYGOTSKY, L. S. Mind in Society - The Development of Higher Psychological Processes. Cambridge MA: Harvard University Press, 1978.

VYGOTSKY, L. S. Pensamento e Linguagem. São Paulo: Martins Fontes, 1998.

WALESKO, A. Formação inicial e o mito do "falante nativo": construções identitárias de professores de inglês em uma comunidade de prática. Tese de Doutorado, Curso de Pós-Graduação em Letras, Setor de Ciências Humanas, Letras e Artes, Universidade Federal do Paraná. Curitiba, 2019. Disponível em: <https://www.prppg.ufpr.br/siga/ 
REVISTA X, Curitiba, volume 14, n.6,p.01-23, 2019.

visitante/trabalhoConclusaoWS?idpessoal=29928\&idprograma=40001016016P7\&anob ase $=2019 \&$ idtc $=1464>$ Acesso em: 20 jul. 2019.

WENGER, E. Communities of Practice: Learning, meaning and identity. New York: Cambridge University Press, 1998. 
REVISTA X, Curitiba, volume 14 , n.6, p. 01-23, 2019.

\section{ANEXOS}

ANEXO 1 - Convenções para transcrição:

\begin{tabular}{|c|c|c|}
\hline - & (ponto final) & entonação descendente \\
\hline$?$ & (ponto de interrogação) & entonação ascendente \\
\hline , & (vírgula) & entonação de continuidade \\
\hline- & (hífen) & marca de corte abrupto \\
\hline$::$ & (dois pontos) & prolongamento do som \\
\hline Nunca & (sublinhado) & sílaba ou palavra enfatizada \\
\hline PALAVRA & (maiúsculas) & fala em volume alto \\
\hline${ }^{\circ}$ palavra $^{\circ}$ & (sinais de graus) & fala em voz baixa \\
\hline$>$ palavra $<$ & $\begin{array}{c}\text { (sinais de maior do que e menor do } \\
\text { que) }\end{array}$ & fala acelerada \\
\hline$\langle$ palavra $>$ & $\begin{array}{c}\text { (sinais de menor do que e maior do } \\
\text { que) }\end{array}$ & fala desacelerada \\
\hline Hh & (série de h’s) & aspiração ou riso \\
\hline$\left[\begin{array}{ll}1 & ]\end{array}\right.$ & (colchetes) & fala simultânea ou sobreposta \\
\hline$(2,4)$ & (números entre parênteses) & $\begin{array}{l}\text { medida de silêncio (em segundos e } \\
\text { décimos de segundos) }\end{array}$ \\
\hline (.) & (ponto entre parênteses) & micropausa, até $2 / 10$ de segundo \\
\hline( & (parênteses vazios) & $\begin{array}{l}\text { segmento de fala que não pôde ser } \\
\text { transcrito }\end{array}$ \\
\hline (palavra) & (segmento de fala entre parênteses) & transcrição duvidosa \\
\hline ((olhando para o teto $))$ & (parênteses duplos) & descrição de atividade não-vocal \\
\hline
\end{tabular}

Adaptado de Atkinson e Heritage (1984, p. ix-Xvi); Ochs, Schegloff e Thompson (1996, p. 461-465); e das instruções para submissão de artigos ao periódico especializado Research on Language and Social Interaction (Lawrence Erlbaum).

ANEXO 2 - propaganda sexista

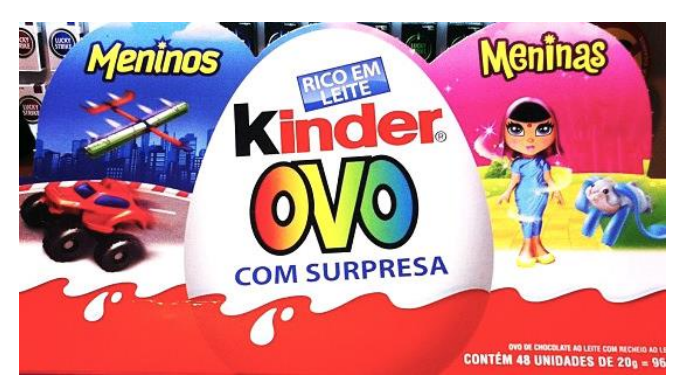


ANEXO 3 - propaganda sexista
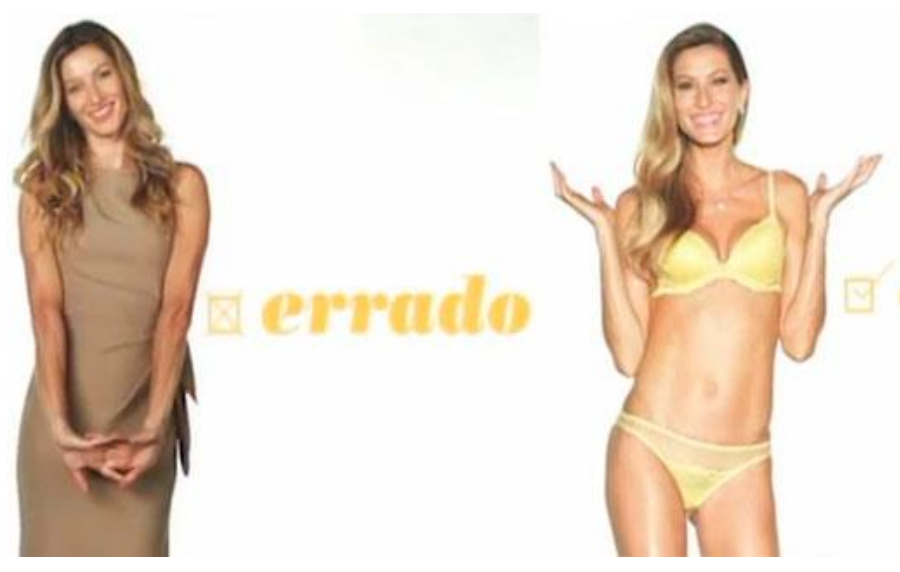

ANEXO 4 - propaganda sexista

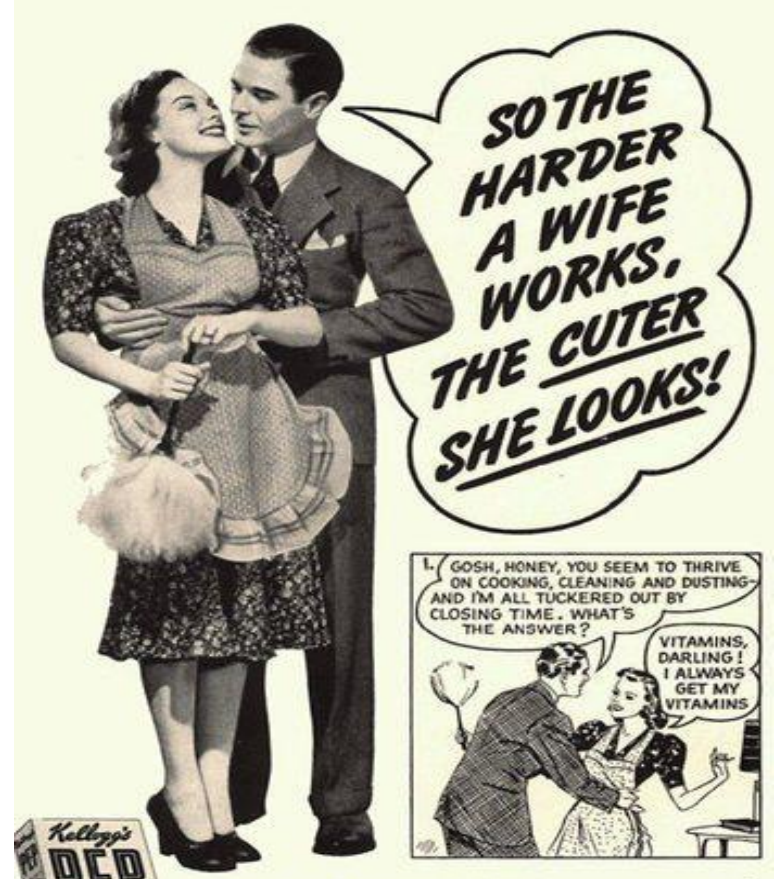

Vitamins for pep! PEP for vitamins!* 